\title{
Integrating Apple iPads into University Computing Courses
}

\author{
Jeffrey A. Stone \\ Pennsylvania State University, Schuylkill Haven, PA, 17972, USA \\ Email: stonej@psu.edu
}

\begin{abstract}
The use of mobile devices is becoming increasingly common in both society and in the K-12 environment. Products such as the Apple iPad and the Microsoft Surface, among others, have matured to a point where university faculty are striving to integrate this increasingly ubiquitous technology into the classroom and the curriculum. This paper represents a case study examining one attempt to integrate the use of tablets into five university-level computing courses during the 20152016 academic year. The author used a set of iPads and accompanying classroom technology (e.g. Apple TV, keyboards) in an attempt to engage students and build their problem-solving and collaborative skills. Student feedback suggests that students were engaged, and the results for the iPad's impact on problem-solving and collaborative skills improved over the course of the year. A number of challenges were observed, including inadequate student knowledge of tablets, wireless connectivity issues, student resistance to the group learning afforded by the iPads, and keeping the tablets charged and clean. Future plans for the study intend to address the challenges uncovered, using student and instructor feedback as an impetus for future development. This paper serves as an experiential report designed to inform other faculty who may be looking into similar projects.
\end{abstract}

Index Terms-iPads, Tablets, Information Science Education, Computer Science Education, Case Studies.

\section{INTRODUCTION}

The use of mobile devices is becoming increasingly common in both society and in the K-12 environment. In higher education, it is not uncommon for students to bring tablet computers to class for note-taking, research and assignment completion. Products such as the Apple iPad and the Microsoft Surface, among others, have matured to a point where some students use them as a replacement for the traditional PC. As educators, university faculty should strive to find ways to integrate this increasingly ubiquitous technology into the classroom and the curriculum.

However, integrating any new technology is not without its challenges. Finding the proper methods in which to integrate tablet computing into university courses is sometimes a daunting task, especially for faculty with little or no technological expertise.
University support, both in terms of resources, training, and technological assistance, is often a critical factor. In addition, leveraging the past experiences of peers can also be helpful by providing a set of best practices as well as pitfalls to avoid.

The computing disciplines, such as Computer Science, Information Science, and Management Information Systems, would seem to be logical places in which to integrate tablet computing. Students and faculty in these disciplines can be expected to have an affinity for technology and a desire to learn more about the possibilities afforded by tablet computing. The iPad is an active learning device, and computing is an active learning discipline. However, little research exists which can provide the experiential knowledge necessary to help university educators integrate tablets into their courses.

The following case study will examine one attempt to integrate the use of tablets into university-level Computer Science (CS), Information Sciences and Technology (IST), and Game Development (GAME) courses. This paper will discuss the equipment and methods utilized over the course of one academic year, as well as student feedback results, challenges, and future plans for enhanced integration. This paper will serve as an experiential report designed to inform other university faculty who may be looking into similar ventures.

This paper is structured as follows. Section II will discuss existing literature and background regarding the use of iPads in university-level courses. Section III will discuss the approach used in this study, including the setting and other contextual factors. Section IV will discuss the data collection procedures utilized, and section $\mathrm{V}$ will discuss the profile of study participants. Sections VI through IX will discuss the results of the data collection, and section $\mathrm{X}$ will discuss the study challenges and lessons learned. Finally, section XI will discuss future plans based on the study results.

\section{BACKGROUND}

Since its introduction in 2010, the Apple iPad has become a rising star in classroom technology. A significant body of literature has grown around the use of iPads in the K-12 environment, often as an alternative for PCs in 1:1 programs [5]. The generally accepted advantages of iPads in education include opportunities for greater student engagement, opportunities for increased collaboration and interaction, and for providing so-called 
21 st century skills, such as creativity and problemsolving [2] [7] [17]. iPads and other mobile devices can be tools for breaking down traditional classroom barriers such as location and time, thus extending the classroom experience and providing customized, personal learning solutions [1] [9].

The disadvantages of using iPads in the classroom have also been recognized. Some studies on iPad implementation have indicated that students, feeling uncomfortable with tablet technology, tend to try and revert to that which is known - PCs. Causal factors have included the difficulties of iPad keyboards, which can be cumbersome for any writing of great length (see [6]). Kheiravar, Lasserre, \& Campbell [10] point out that modern tablets were designed to overcome previouslyheld concerns about screen size and limited software libraries. In addition, the wireless "freedom" provided by the iPad can result in off-task use, such as social media and Web surfing [17].

A review of the existing iPad literature by Nguyen, Barton, \& Nguyen [12] pointed out the immaturity of research into university-level iPad integration. This study found that while the iPad has generated much interest among academics, the existing research studies have been inconclusive as it pertains to learning outcomes. Student engagement is the primary learning outcome observed, and more systematic and long-term studies are necessary to explore the iPad's impact on learning.

Several experiential reports on iPad rollouts to university faculty exist in the literature, though they tend to be from the technology services perspective (e.g. [3], [16]). In contrast, Mang \& Wardley [11] take an instructional design perspective in describing an iPad implementation and the lessons learned. These authors described how they used the iPads to distribute lecture notes, have students perform research, and perform routine quizzing of students. The iPads were also used for structured activities; for example, students were asked to conduct research and share their results with the class, facilitating group work and promoting face-to-face interaction. Students created their own documents and shared their thoughts with the class via an online learning management system.

Much of the existing literature for iPad-related, university-level instruction focuses on the concepts of "screencasts" and related concepts. For example, Palmer [13] discusses the use of "touchcasting", i.e. preparing touch-generated multimedia presentations for a CS algorithms course. Silverberg [14] and Silverberg, Tierney, and Bodek [15] provide examples of how to use iPads and Doceri software to provide content for online and residential chemistry courses. Using Doceri and similar software, instructors can present slides and annotate them during the presentation. These annotations can then be saved, uploaded to a shared site, and downloaded by students for later review. Instructors can also use the software as a virtual whiteboard, where figures can be drawn by both students and instructors during lecture. Hesser \& Schwartz [8] discussed the use of iPads as a laboratory tool, for recording experiment results and submitting lab reports in a college-level chemistry course.

The research on the use of tablet computers in CS education is limited. Ihantola, Helminen, \& Karavirta [9] discussed the creation of software that allows students to learn Python programming. Their solution accommodates the smaller screen space of the iPad (and related devices) by leveraging drag-and-drop touch functionality while providing for code customization. These researchers point out the problems involved with writing code on a mobile device - the limited screen space, the special characters that need to be used, and the insufficient nature of many existing programming apps - and offer a custom solution. The idea of a custom app for mobile devices is also common in the human-computer interaction literature, such as apps for collaborative work (e.g. [10]). Other CS education literature focuses on the use of iPads as a development platform for higher level courses (see [4]).

\section{THE CASE STUDY}

In early 2015 the author applied for an internal grant that would permit the use of tablet computers in a diverse set of computing-centric courses. The funded grant provided an Apple TV, a set of six (6) iPad Air tablets, styluses and vinyl cases for use in the classroom. A second Apple TV from an earlier purchase was also available for use in this project. An additional set of five (5) Bluetooth keyboards was also obtained prior to the spring 2016 semester. HDMI-to-VGA adapters were obtained to allow the Apple TV to work with two existing collaboration stations. One of the iPads was reserved for use by the author, leaving five (5) iPads for student use.

The study described in the remainder of this paper was designed to allow the author to experiment with these iPads and the Apple TV technology in freshmen- and sophomore-level computing courses at a small satellite campus of a large public research university. The expectation was that these technologies would help promote student engagement and classroom mobility, while providing opportunities for students to use existing collaboration stations within the classroom. Beyond these expectations, the goals for the project were to facilitate the building of collaborative and problem-solving skills among the participating students. The fundamental research questions were as follows:

- Do students perceive a positive impact from the integration of iPads?

- Do students perceive the course as having a positive impact on their collaborative skills?

- Do students perceive the use of iPads as having a positive impact on their collaborative skills?

- Do students perceive the course as having a positive impact on their problem-solving skills?

- Do students perceive the use of iPads as having a positive impact on their problem-solving skills? 


\section{A. Methodology}

The Apple TV and five (5) iPads were integrated by the author into five courses over the course of two 15week semesters (fall and spring) during the 2015-2016 academic year. These courses included introductory courses in IST (one section); CS (one general education section, one section for engineers and CS majors); and a GAME course on video game culture (one section). The iPads were also utilized in one section a senior-level IST course on data visualization.

All of the participating course sections were taught by the author and utilized the same classroom. The classroom is a technology-focused classroom, complete with Smartboard and computers at every desk (see Fig. 1) The classroom also has two collaboration stations with seating for five, power outlets, and connectivity for computing devices. Two large LCD monitors can be used at each collaboration station. See Fig. 2 for a visual representation of the collaboration stations.

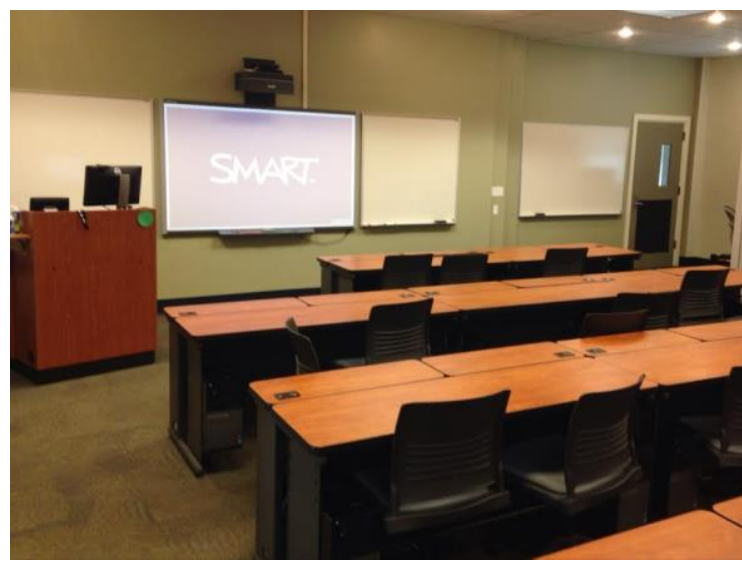

Fig.1. Classroom

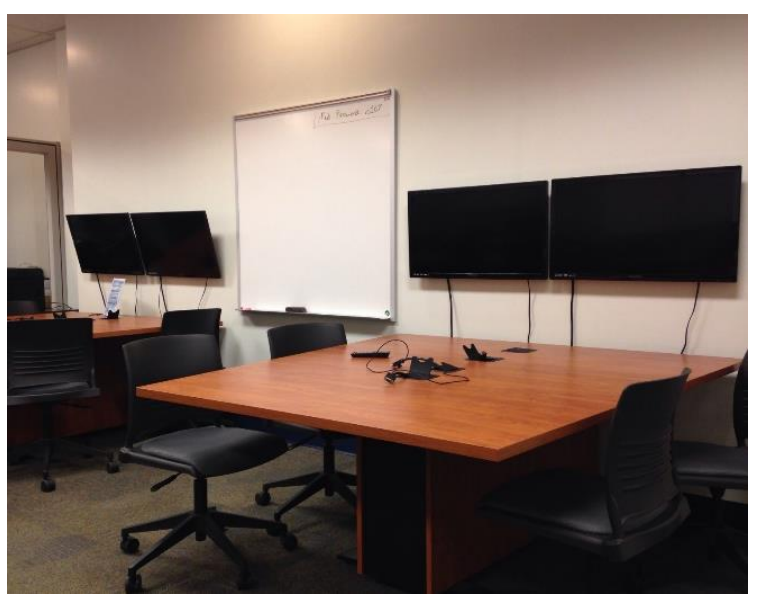

Fig.2. Collaboration Stations

The number of students involved in these course sections ranged from two (2) to twenty (20). As a result, the limited number of iPads meant that accommodations were made when they were used in the classroom. More often than not, team activities were used to facilitate collaboration. Students would also sometimes "rotate" using the iPads for various activities. For example, a subset of students would use the iPads during one class, and then others would use it to complete the activity during the next class. In other cases, some students would use the iPad for one activity and the remaining students would use the iPad for a subsequent, similar activity.

\section{B. Use of iPads in the Classroom}

The author was able to use the iPad primarily as a vehicle for presenting lecture notes, while walking around the classroom and engaging students directly during lecture-based discussions. In terms of student use, a decision was made at the beginning of the project to integrate the iPads only where appropriate. The iPads were used as a minor part of each course, one which did not dominate the course content but was interjected at points in which it was felt they would assist in achieving the stated course and study goals. Activities were structured based on the course content and the number of participating students. The course LMS (Canvas) and its mobile app were integrated in all iPad-based activities.

For the introductory CS courses, students utilized the iPads in small teams to perform problem-solving activities. The first few weeks of the course is spent building flowcharts for simple problems. Participating students would use the LucidChart application (http://www.lucidchart.com) to build their flowcharts and share them with the instructor, both on the PC and using the iPad app. While the problem domains varied, one of these iPad-based LucidChart activities tasked students with building a flowchart to describe how to set an alarm and a reminder on the iPad.

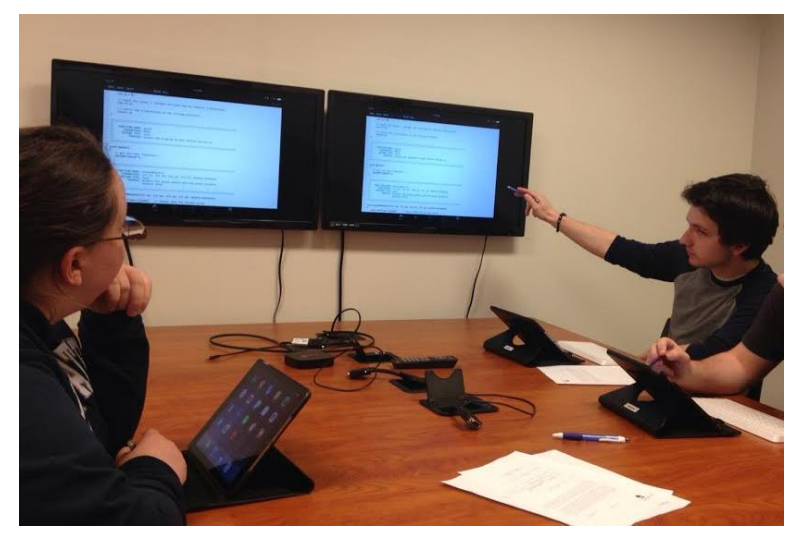

Fig.3. Using the iPads and a Collaboration Station

The bulk of the introductory CS courses involved programming solutions to simple problems in $\mathrm{C}++$. During this portion of the course, students would periodically work in teams at the collaboration stations to write simple $\mathrm{C}++$ code with the iPads. These activities took one of two forms. The first form involved completing custom code activities using Websheets (http://cscircles.cemc.uwaterloo.ca/websheets/about.html) via the Google Chrome app. The second form involved a custom activity whereby students, using an iPad-based $\mathrm{C}++$ compiler, completed code for a unit test and integrated a user-defined function into a larger program (see Fig. 3). The instructor also leveraged the iPad's 
mobility by actively creating code during lecture (projected to the Smartboard via Apple TV) and periodically handing the iPad off to a student, who would then complete a few lines of the program.

For the introductory IST course, the iPad-based activities focused on allowing students to perform simple, collaborative research and construct information products describing their findings. In addition, student teams would present these products and their findings to the class. The Keynote, Pages, and iMovie apps were used to construct the information products, and the activities were designed to be completed within a single class period. Given that this course is both an IST major requirement and a general education course, the technological ability of the students varied widely; consequently, a decision was made to focus on comparatively simple tasks to acclimate the students to the iPads and their functions.

Most activities in the introductory IST course included performing a small reading and creating a response or position statement, though one activity was designed to allow the user to experiment with the iMovie app (whose Mac-based equivalent was to be used as part of a larger, semester-long team project). In all cases, students' collaborative work was shared with the class via the Apple TV. Students would connect via Bluetooth from their seats, and then verbally discuss the information products they'd created. During these presentations, students would either remain seated or venture with their iPad to the front of the room.

For the survey course in video game culture, an approach similar to the introductory IST course was taken. The iPad-based activities focused on allowing students to perform collaborative research and construct information products using the Keynote and Pages apps. The activities were designed to be completed within a single class period. Most activities included performing some Webbased research and/or playing a Web-based game, after which the student teams would construct a response to several instructor-provided questions. Students' collaborative work was then shared with the class via the Apple TV. Students would again connect via Bluetooth from their seats, and then present their information products. During these presentations, students would usually remain seated.

For the higher-level IST course on data visualization, the iPads were utilized on an individual basis over a three-week period. Each student was tasked with creating a visualization using the Codea Scratchpad app (https://codea.io/scratchpad/). After some initial in-class demonstrations, students used the iPads each day to construct their visualization. At the end of the project, students presented their work. Students connected to the Apple TV via Bluetooth from their seats, after which they would demonstrate their visualization, discuss their approach, and field questions.

\section{DAta COLlection PROCEDURES}

Data collection occurred at the end of both the fall and spring semesters. A survey was constructed to measure student perceptions of the impact of the iPads, the perceived impact of the course on collaborative skills, the perceived impact of the course on problem-solving skills, and general course outcomes. The survey was delivered to two (2) fall semester course sections and three (3) spring semester course sections. In all cases the survey was delivered to students during the final week of classes. The survey was modified between the two semesters to correct a misspelling and to add one question. Survey data was collected using the SurveyMonkey.com site and analyzed using SPSS. The data collection and study were approved by the Penn State Office of Research Protections.

\section{PRofile of PARTicipants}

A total of 12 students completed the fall 2015 survey, representing $66.7 \%$ of the available population. All of the respondents were from one course section (the intro CS course), as students in the second course section declined to participate. Most of the respondents were male (83.3\%, $\mathrm{N}=12)$, between $18-30$ years old $(91.7 \%)$, and reported themselves as White/Caucasian $(91.7 \%)$. There was more diversity in the academic class level; see Table 1. Despite the general education nature of the course, most students identified as Computer Science or Information Science and Technology majors $(91.7 \%, \mathrm{~N}=12)$. In terms of Math background, all but one student reported taking (or have taken) college-level algebra or above $(91.7 \%, \mathrm{~N}=12)$.

Table 1. Distribution in Participants' Academic Class Level

\begin{tabular}{lcc}
\hline Student Class & Fall 2015 & Spring 2016 \\
\hline Freshmen & $5(41.7 \%)$ & $15(53.6 \%)$ \\
Sophomores & $4(33.3 \%)$ & $11(39.3 \%)$ \\
Juniors & $2(16.7 \%)$ & $1(3.6 \%)$ \\
Seniors & $1(8.3 \%)$ & $1(3.6 \%)$ \\
\hline
\end{tabular}

Combining the participation across the three course sections, a total of 29 students completed the spring 2016 survey. This participation represented $76.3 \%$ of the available population. A majority of the respondents were male $(69.0 \%, \mathrm{~N}=29)$ and between $18-30$ years old $(93.1 \%)$. Most respondents reported themselves as White/Caucasian $(62.1 \%, \mathrm{~N}=29)$, while $20.7 \%$ identified as Asian/Asian-American and $6.9 \%$ identified as Latino/Hispanic. Once again, there was diversity in the academic class level (see Table 1). A majority of students identified as Computer Science or Information Science and Technology majors $(41.4 \%, \mathrm{~N}=29)$. All but three students reported taking (or have taken) college-level algebra or above $(89.7 \%, \mathrm{~N}=29)$. 


\section{STUdy RESUltS: GENERAL COURSE OUTCOMES}

Students were asked to report their level of agreement with multiple questions gauging their perceptions of the course outcomes. These questions were statements followed by a Likert-style scale rating the students' level of agreement (1=Strongly Agree, 2=Agree, 3=Neutral (Undecided), 4=Disagree, 5=Strongly Disagree). The results show students had a very positive perception of their own learning and the applicability of the courses to their future endeavors.

\section{A. Fall 2015}

The first statement was I am able to visualize the ideas and concepts taught in this course. More than threefourths of the respondents agreed or strongly agreed with the statement $(83.3 \%$ total, $\mathrm{N}=12)$. The other $16.7 \%$ were neutral. The mean response was 1.92 and the median was 2.00.

Students were then given the statement I understand the ideas and concepts taught in this course. The majority of respondents agreed or strongly agreed with the statement $(75.0 \%, \mathrm{~N}=12)$. The remaining $25.0 \%$ were neutral. The mean was 2.00 and the median was 2.00 .

The vast majority of respondents agreed or strongly agreed with the statement I have acquired skills in this course that will be useful in my chosen profession $(91.7 \%$ total, $\mathrm{N}=12$ ). The other $8.3 \%$ disagreed with the statement. The mean response was 1.50 and the median was 1.00 .

The vast majority of respondents agreed or strongly agreed with the statement I have acquired skills in this course that will be useful in my future college courses ( $91.7 \%$ total, $\mathrm{N}=12$ ). The other $8.3 \%$ were neutral. The mean response was 1.50 and the median was 1.00 .

Finally, students were given the statement Assignments and activities for this course encouraged me to exercise my creativity. The majority of respondents agreed or strongly agreed with the statement $(54.6 \%, \mathrm{~N}=11)$. One respondent disagreed with the statement $(9.1 \%)$ and four were neutral $(36.4 \%)$. The mean response was 2.36 and the median was 2.00 .

\section{B. Spring 2016}

Students again responded positively to the statement $I$ am able to visualize the ideas and concepts taught in this course. More than three-fourths of the respondents agreed or strongly agreed with the statement $(89.7 \%$ total, $\mathrm{N}=29)$. The other $10.3 \%$ were neutral. The mean response was 1.72 and the median was 2.00 .

Virtually all the respondents agreed or strongly agreed with the statement $I$ understand the ideas and concepts taught in this course (96.6\% total, $\mathrm{N}=29)$. Only one respondent was neutral $(3.4 \%)$. The mean response was 1.69 and the median was 2.00 .

A majority of the respondents agreed or strongly agreed with the statement I have acquired skills in this course that will be useful in my chosen profession (58.6\% total, $\mathrm{N}=29$ ). The other respondents were either neutral $(31.0 \%)$ or disagreed with the statement $(10.3 \%)$. The mean response was 2.24 and the median was 2.00 . There was a significant difference between males (mean $=2.00$, sd $=0.918)$ and females $($ mean $=2.78, \mathrm{sd}=0.972)$ in responses to this question $(\mathrm{t}=-2.075, \mathrm{df}=27, \mathrm{p}<0.05)$.

A majority of the respondents agreed or strongly agreed with the statement I have acquired skills in this course that will be useful in my future college courses $(75.9 \%, \mathrm{~N}=29)$. The other respondents were either neutral $(17.2 \%)$ or disagreed with the statement $(6.9 \%)$. The mean response was 1.90 and the median was 2.00 .

The vast majority of the respondents agreed or strongly agreed with the statement Assignments and activities for this course encouraged me to exercise my creativity ( $86.2 \%$ each, $\mathrm{N}=29$ ). The remaining $13.8 \%$ were neutral. The mean response was 1.79 and the median was 2.00 .

\section{STUdY RESUltS: PROBLEM-SOLVING SKILLS}

Students were asked to report their level of agreement with multiple questions gauging their perceptions of how the course impacted their problem-solving skills, using the same Likert-style scale as previously mentioned. Student responses were very positive in their assessment of the courses' inclusion of problem-solving techniques and its applicability to other domains.

\section{A. Fall 2015}

The first statement was This course helped me learn to work through a process to solve problems. All respondents agreed or strongly agreed with the statement $(\mathrm{N}=12)$. The mean response was 1.67 and the median was 2.00. See Fig. 4.

Students were then given the statement I have acquired skills in this course that I can transfer to other problemsolving activities. All but one respondent agreed or strongly agreed with the statement $(91.7 \%, \mathrm{~N}=12)$. The other student was neutral. The mean response was 1.58 and the median was 1.50 .

\section{B. Spring 2016}

More than three-fourths of the respondents agreed or strongly agreed with the statement This course helped me learn to work through a process to solve problems (79.3\% total, $\mathrm{N}=29$ ). Only $3.4 \%$ disagreed and $17.2 \%$ were neutral. The mean response was 2.00 and the median was 2.00. See Fig. 4.

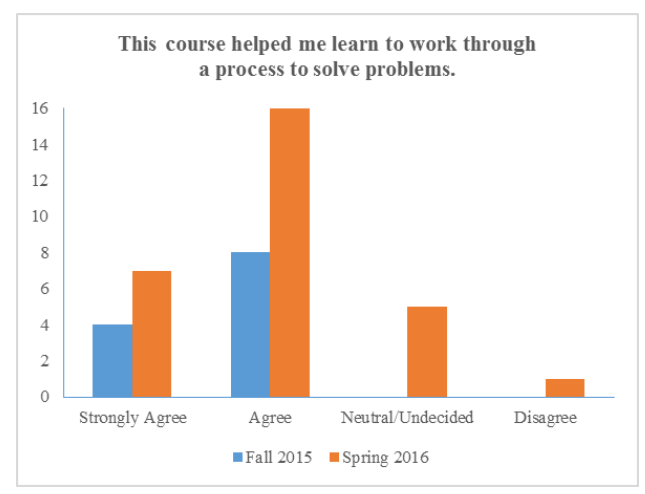

Fig.4. Perception of Problem-Solving Integration 
Once again, more than three-fourths of the respondents agreed or strongly agreed with the statement I have acquired skills in this course that I can transfer to other problem-solving activities ( $82.8 \%$ each, $\mathrm{N}=29$ ). The remaining respondents were primarily neutral $(13.8 \%)$ with $3.4 \%$ disagreeing with the statement. The mean response was 1.83 and the median was 2.00 .

\section{STUDY RESULTS: PERCEIVED IPAD IMPACT}

Students were asked to report their level of agreement with multiple questions gauging their perceptions and attitudes on the course integration of iPads, using the same Likert-style scale as previously mentioned. The alpha coefficient suggests these items have internal consistency in both semesters (fall: $\alpha=0.954$; spring: $\alpha=$ 0.923). Means and medians for the specific questions are reported in Table 2.

\section{A. Fall 2015}

The first statement was The use of iPads in this course enhanced my learning experience. More than one-half of respondents agreed or strongly agreed with the statement ( $58.3 \%$ total, $\mathrm{N}=12$ ). The remaining $41.7 \%$ were neutral.

Students were then given the statement The iPads were used effectively in this course. Once again, more than one-half of respondents agreed or strongly agreed with the statement $(58.3 \%$ total, $\mathrm{N}=12)$. The remaining $41.7 \%$ were neutral.

Results were more diverse for the statement Because of the way this course uses iPads...I am better able to visualize the ideas and concepts taught in this course. A small number of the respondents agreed or strongly agreed with the statement (33.3\% total, $\mathrm{N}=12)$ while $50.0 \%$ were neutral and $16.7 \%$ disagreed.
Students were then given the statement Because of the waythis course uses iPads...I am better able to understand the ideas and concepts taught in this course. A small number of the respondents agreed or strongly agreed with the statement $(41.7 \%$ total, $\mathrm{N}=12)$ while an equal amount were neutral $(41.7 \%)$. The remaining $16.7 \%$ disagreed.

Less than one-half of the respondents agreed or strongly agreed with the statement Because of the way this course uses iPads...I am acquiring skills that I can transfer to other problem-solving activities $(41.7 \%$ total, $\mathrm{N}=12$ ) while $50.0 \%$ were neutral and $8.3 \%$ disagreed.

A minority of respondents agreed or strongly agreed with the statement Because of the way this course uses iPads...I am better able to communicate my ideas to others $(33.3 \%$ total, $\mathrm{N}=12)$ while $50.0 \%$ were neutral and $16.7 \%$ disagreed.

A majority of respondents strongly agreed or agreed with the statement Because of the way this course uses iPads for group activities...I have acquired skills for working collaboratively with small groups (58.3\% total, $\mathrm{N}=12$ ) while the remaining $41.7 \%$ were neutral.

Students were then given the statement Because of the way this course uses iPads...I am acquiring skills that will be useful in my chosen profession. The majority of respondents agreed or strongly agreed with the statement (50.0\% total, $\mathrm{N}=12$ ) while $41.7 \%$ were neutral and $8.3 \%$ disagreed.

Finally, students were given the statement Because of the way this course uses iPads...I am acquiring skills that will be useful in my future college courses. The majority of respondents agreed or strongly agreed with the statement $(50.0 \%$ total, $\mathrm{N}=12)$ while $41.7 \%$ were neutral and $8.3 \%$ disagreed.

Table 2. Survey Means and Medians for Perceived iPad Impact Questions

\begin{tabular}{lcccc}
\hline & \multicolumn{2}{c}{ Fall 2015 } & \multicolumn{2}{c}{ Spring 2016 } \\
Survey Question & Mean & Median & Mean & Median \\
\hline The use of iPads in this course enhanced my learning experience. & 2.33 & 2.00 & 2.07 & 2.00 \\
The iPads were used effectively in this course & 2.25 & 2.00 & 1.76 & 2.00 \\
Because of the way this course uses iPads... & & & & \\
...I am better able to visualize the ideas and concepts taught in this course. & 2.75 & 3.00 & 2.48 & 3.00 \\
...I am better able to understand the ideas and concepts taught in this course. & 2.67 & 3.00 & 2.45 & 2.00 \\
...I am acquiring skills that I can transfer to other problem-solving activities & 2.58 & 3.00 & 2.14 & 2.00 \\
...I am better able to communicate my ideas to others & 2.75 & 3.00 & 2.38 & 2.00 \\
... I have acquired skills for working collaboratively with small groups & 2.25 & 2.00 & 2.10 & 2.00 \\
....I am acquiring skills that will be useful in my chosen profession. & 2.50 & 2.50 & 2.41 & 2.00 \\
...I am acquiring skills that will be useful in my future college courses. & 2.50 & 2.50 & 2.21 & 2.00 \\
\hline \multicolumn{2}{c}{ Scale: 1=Strongly Agree, 2=Agree, 3=Neutral (Undecided), 4=Disagree, 5=Strongly Disagree } \\
\hline
\end{tabular}

\section{B. Spring 2016}

More than two-thirds of the respondents agreed or strongly agreed with the statement The use of iPads in this course enhanced my learning experience $(34.5 \%$ each, $\mathrm{N}=29$ ). Only $10.3 \%$ disagreed and $20.7 \%$ were neutral. Goodman and Kruskal's gamma analysis found moderate, positive, statistically significant correlations between responses to this question and two others: I am able to visualize the ideas and concepts taught in this course $(\gamma=0.550, \mathrm{p}<0.05)$ and Assignments and activities for this course encouraged me to exercise my creativity $(\gamma=0.514, \mathrm{p} \leq .01)$.

More than three-fourths of the respondents agreed or strongly agreed with the statement The iPads were used effectively in this course (41.4\% each, $\mathrm{N}=29)$. The remaining $17.2 \%$ were neutral. Goodman and Kruskal's gamma analysis found a strong, positive, statistically 
significant correlation between responses to this question and Assignments and activities for this course encouraged me to exercise my creativity $(\gamma=0.750, p$ $<.01)$. A moderate, positive, statistically significant correlation between responses to this question and I am able to visualize the ideas and concepts taught in this course was also found $(\gamma=0.570, \mathrm{p}<0.05)$.

Results were more diverse for the statement Because of the waythis course uses iPads...I am better able to visualize the ideas and concepts taught in this course. A majority of the respondents agreed or strongly agreed with the statement $(48.3 \%$ total, $\mathrm{N}=29)$, but $34.5 \%$ were neutral and $17.2 \%$ disagreed.

The majority of respondents agreed or strongly agreed with the statement Because of the way this course uses iPads...I am better able to understand the ideas and concepts taught in this course $(55.2 \%$ total, $\mathrm{N}=29)$ while $24.1 \%$ were neutral and $20.7 \%$ disagreed.

Results were very positive for the statement Because of the way this course uses iPads...I am acquiring skills that I can transfer to other problem-solving activities. More than two-thirds of the respondents agreed or strongly agreed with the statement (71.4\% total, $\mathrm{N}=28)$. The other respondents were neutral $(21.4 \%)$ or disagreed $(7.1 \%)$.

The majority of respondents agreed or strongly agreed with the statement Because of the way this course uses iPads...I am better able to communicate my ideas to others (62.1\% total, $\mathrm{N}=29)$ while $24.1 \%$ were neutral and $13.8 \%$ disagreed.

The vast majority of respondents agreed or strongly agreed with the statement Because of the way this course uses iPads for group activities...I have acquired skills for working collaboratively with small groups $(65.5 \%$ total, $\mathrm{N}=29$ ) while $24.1 \%$ were neutral and $10.3 \%$ disagreed.

Students were then given the statement Because of the way this course uses iPads...I am acquiring skills that will be useful in my chosen profession. The majority of respondents agreed or strongly agreed with the statement (55.2\% total, $\mathrm{N}=29$ ) while $27.6 \%$ were neutral and $17.2 \%$ disagreed. Goodman and Kruskal's gamma analysis found a weak, positive, statistically significant correlation between responses to this question and I have acquired skills in this course that will be useful in my chosen profession $(\gamma=0.451, \mathrm{p}<.05)$.

The majority of respondents agreed or strongly agreed with the statement Because of the way this course uses iPads....I am acquiring skills that will be useful in my future college courses $(62.1 \%$ total, $\mathrm{N}=29)$ while $27.6 \%$ were neutral and $10.3 \%$ disagreed. A weak, positive, statistically significant correlation was found between responses to this question and I have acquired skills in this course that will be useful in my future college courses $(\gamma=0.451, \mathrm{p}<.05)$.

\section{Discussion}

Overall, the results show a generally positive outlook on the impact of the iPads, though this positivity was observed more so in the spring semester than in the fall. Students tended to agree that the iPads enhanced the learning experience and were used effectively, suggesting that student engagement was high. Students were slightly less enthusiastic in the fall, however, when it came to the iPads impact on problem-solving, collaborative learning, and other outcomes. In sum, the results are fitting the pilot nature of the study: the initial year is a time for experimentation and refinement. The more positive spring results suggest that adjustments made between semesters had a positive effect, though the increased number of participating students was certainly a factor. The addition of the keyboards may have also impacted the more positive results in the spring. Success in any future iPad integration may be served by educating students on the value of the iPads for the stated outcomes, as well as further integrating the iPad and related technologies into the courses.

\section{STUDY RESUlTS: COLLABORATIVE SKILLS}

Students were asked to report their level of agreement with multiple questions gauging their perceptions of how the course impacted their collaboration skills.

\section{A. Fall 2015}

The first set of statements utilized the aforementioned Likert-style scale. The first statement was This course helped me learn to work collaboratively with small groups. The majority of respondents agreed or strongly agreed with the statement (See Fig. 5). The mean response was 2.58 and the median was 3.00.

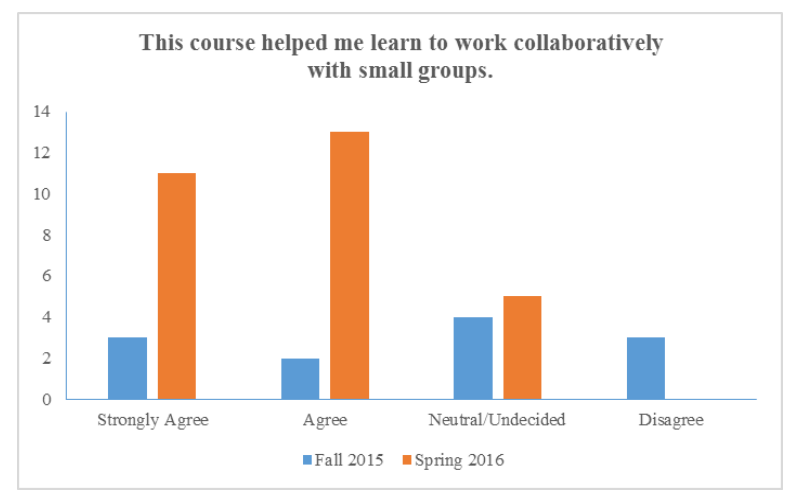

Fig.5. Perception of Course Impact on Collaborative Skills

The next statement was Group work in this course has helped me to understand the ideas and concepts being taught. The majority of respondents agreed or strongly agreed with the statement $(66.7 \%$ total, $\mathrm{N}=12)$ while $25.0 \%$ were neutral. Only one respondent disagreed with the statement. The mean response was 2.17 and the median was 2.00 .

Students were also asked to identify the frequency at which they participated in course-related collaborative activities. Students were given a three-level scale for reporting the frequency $(1=$ None/not at all, 2=One or two times, $3=$ Three or more times) of four distinct activities.

Students were first asked about how frequently they Studied with other students for quizzes and/or examinations for this course. The results show that students most often studying for quizzes and exams with 
others one or two times $(50.0 \%$ each, $\mathrm{N}=12)$. A greater number of students were neutral $(33.3 \%)$ than reported studying with others three or more times $(16.7 \%)$. The mean was 1.83 and the median was 2.00.

However, when students were asked about how frequently they Worked on an assignment for this course with one or more other students, the results suggest a higher level of collaboration. The majority of respondents reporting collaborating with others one or two times $(58.3 \%, \mathrm{~N}=12)$ with $42.9 \%$ reporting collaborating three or more times. The mean was 2.42 and the median was 2.00 .

Students were next asked about how frequently they Discussed the ideas and concepts taught in this course with other students. The majority of respondents reporting collaborating with others three or more times $(66.7 \%, \mathrm{~N}=12)$ with $33.3 \%$ reporting collaborating one or two times. The mean was 2.67 and the median was 3.00.

Finally, students were asked about how frequently they Assisted other students who ask for help with work for this course. The majority of respondents reporting assisting others one or two times $(66.7 \%, \mathrm{~N}=12)$ and $33.3 \%$ reporting assisting others three or more times. The mean was 2.17 and the median was 2.00.

\section{B. Spring 2016}

More than three-fourths of the respondents agreed or strongly agreed with the statement This course helped me learn to work collaboratively with small groups (See Fig. 5). The mean response was 1.79 and the median was 2.00 .

More than three-fourths of the respondents agreed or strongly agreed with the statement Group work in this course has helped me to understand the ideas and concepts being taught $(75.9 \%$ total, $\mathrm{N}=29)$. The remaining $24.1 \%$ were neutral. The mean response was 1.83 and the median was 2.00. Goodman and Kruskal's gamma was run to determine the association between responses to this statement and Because of the way this course uses iPads for group activities...I have acquired skills for working collaboratively with small groups. There was a weak, positive statistically significant correlation between responses $(\gamma=0.458, \mathrm{p}<.05)$.

An additional question regarding collaboration was added to the spring survey. The vast majority of respondents agreed or strongly agreed with the statement I understand the value of working collaboratively in small groups $(86.2 \%$ total, $\mathrm{N}=29)$ while $9.68 \%$ were neutral. Only one student disagreed with the statement. The mean response was 1.69 and the median was 2.00. Goodman and Kruskal's gamma was run to determine the association between responses to this statement and Because of the way this course uses iPads for group activities...I have acquired skills for working collaboratively with small groups. There was a moderate, positive statistically significant correlation between responses $(\gamma=0.579, \mathrm{p}<.01)$.

Students were again asked to identify the frequency at which they participated in course-related collaborative activities. When students were asked about how frequently they Studied with other students for quizzes and/or examinations for this course, the results again showed that students did not frequently collaborate in studying for quizzes and exams. The majority reported not collaborating at all $(61.1 \%, \mathrm{~N}=29)$. The mean was 1.48 and the median was 1.00 .

However, when students were asked about how frequently they Worked on an assignment for this course with one or more other students, the results again suggest a much higher level of collaboration. The majority of respondents reported collaborating with others three or more times $(62.1 \%, \mathrm{~N}=29)$ with $20.7 \%$ reporting collaborating one or two times and $17.2 \%$ reporting no collaboration. The mean was 2.45 and the median was 3.00. Goodman and Kruskal's gamma analysis found moderate, positive, statistically significant correlations - adjusting for inverse scales - between responses to this question and two others: This course helped me learn to work collaboratively with small groups $(\gamma=0.587, \mathrm{p}<.05)$ and Group work in this course has helped me to understand the ideas and concepts being taught $(\gamma=0.571, \mathrm{p}<.05)$.

When asked about how frequently they Discussed the ideas and concepts taught in this course with other students, the majority of respondents reporting discussing concepts with others three or more times $(65.5 \%, \mathrm{~N}=29)$ with $34.5 \%$ reporting discussing concepts one or two times. The mean was 2.66 and the median was 3.00 .

The majority of respondents reporting assisting others one or two times when asked about how frequently they Assisted other students who ask for help with work for this course $(48.3 \%, \mathrm{~N}=29)$. A total of $27.6 \%$ reported assisting others three or more times and $24.1 \%$ reported never having assisted other students. The mean was 2.03 and the median was 2.00 .

\section{Discussion}

The survey results show that students felt that the courses helped them to learn collaborative skills (especially in the spring) and that group work assisted them in understanding course concepts. Statistically significant correlations suggest that classroom use of the iPads were assistive in these results but it is also possible that students' own group work outside the classroom played a large role. Students in both semesters collaborated with others most frequently in discussing course concepts and working on assignments, though a distinction between out-of-class and in-class was not made for these questions.

\section{Study RESUlts: StUdent COMMENTS}

Students were given an open-ended question near the end of the survey in which to offer their feedback on the iPad integration. The question posed was: Based on how iPads were used in this course, what advice or recommendations do you have to help us improve the use of iPads in future course sections?

\section{A. Fall 2015}


There were 12 student responses to the open-ended question at the end of the fall semester. Five $(41.7 \%)$ responses mentioned that the iPads should be used more often (e.g. "I feel like in this class we didn't use the iPads to their full potential and that we could have done more collaborative work with them"). Only one student felt they should not be used in the future. Three responses (25.0\%) mentioned the inherent difficulty in writing code on the iPads, such as stylus-related precision and typing using the virtual keyboard. Other responses were suggestions, such as scenarios that could be used in class.

\section{B. Spring 2016}

There were 29 student responses to the open-ended question at the end of the spring semester. Of these responses, eight $(27.6 \%)$ mentioned that the iPads should be used more, and three $(10.3 \%)$ remarked that more iPads were needed. One student even commented that "We should use iPads instead of the computers." The iPads did not appeal to all students, however; two (6.9\%) remarked that they didn't feel the iPads were needed at all. The addition of Bluetooth keyboards in the spring was also mentioned by five $(17.2 \%)$ respondents, largely as something that should be used more often (the keyboard was not used for all activities). Two respondents $(6.9 \%)$ remarked that some sort of iPad orientation at the onset of the class would also be helpful.

\section{CHALlENGES AND LESSONS LEARNED}

Over the course of the year several important challenges were encountered. Many of these challenges could have been avoided with proper testing and foresight. However, being an "experiment", much of the lessons important for a smooth operation were learned during the classroom integration.

\section{A. Student Challenges}

The author noted extreme diversity in prior student knowledge of tablet computing devices. While all students appear to be well-versed in using their cell phones, this knowledge did not necessarily translate to tablet computers. The author made the initial mistake of assuming that students would easily learn to use the iPads and, thus, there was no formal effort made to "train" the students. Consequently, some struggled out of the gate when using the iPads. Others relied on the knowledge of their teammates; the author observed several occasions where one "guru" student in each of the groups would dominate the actual use of the iPad while their teammates participated in other ways. Over time, all students became proficient in using the iPads for the class activities.

There were a non-trivial number of students who resisted using the iPad. Some expressed a desire to use the classroom computers instead. The problem seemed to be that the iPad (and specifically its size) forced teams of two-three students to collaborate through verbal and other means, rather than simply having each person do their own electronic portion of the activity. In this sense, the iPads forced the students to verbally collaborate with each other rather than simply divide the work amongst the members. This change was not always welcomed.

\section{B. Equipment Challenges}

While the iPads generally functioned well, problems with connecting to the campus network were sometimes an issue. The wireless connection for each iPad would periodically disconnect, interrupting the present activity by forcing the user to re-authenticate. This was likely due to the campus-level security restrictions placed on the iPads, which caused the wireless network profile to periodically be deleted. No remediation was found over the course of the year, though campus IT support was made aware of the issue. A parallel issue was encountered using the university-specific software for connecting Apple TV to the campus network. In this instance, an iOS update during the fall rendered the software incompatible, making it impossible to connect the Apple TV (and, by extension, the iPads) to the Smartboard screen. Though the software was eventually updated, Bluetooth was used as a workaround for the remainder of the year.

Another concern observed was students' use of the provided stylus. By and large, students seemed to expect a high level of precision with the stylus. While the Microsoft Surface has made great strides in this area, the third-party stylus for the iPad did not allow for similar precision. As a result, students became frustrated at times with the stylus, especially when moving the cursor to correct a typo. In the future, we hope to obtain styluses (and apps) with greater precision capability and educate the students about what to expect.

Finally, students would sometimes get frustrated with the screen size. This was sometimes a problem during group activities, especially for those groups who were not using the collaboration stations. We learned that some of the apps we were using do not allow users to zoom, further complicating the situation. Groups were encouraged (not required) to use the LCD screens found at the collaboration stations, but many groups chose to remain at their set of desks. In the future, we plan to require use of the collaboration stations where possible and further develop activities which can leverage those stations for maximum effect. A review of the apps utilized will, hopefully, lead us to utilize a set of apps that is more flexible for our activities.

\section{Management Challenges}

One management problem for the author was keeping the devices clean of fingerprints and dirt. Though a stylus was provided, many students preferred to use their fingers - no doubt due to the familiarity of such input from their cell phones. Simple electronics wipes were used to clean the tablets.

Remembering to charge the tablets and the keyboards was also a minor challenge, as well as managing the tangle of wires necessary to do so in a small faculty office. Future grant work will include the purchase of one or more charging stations for the devices. 
One interesting management problem was found with our collaboration stations. We initially failed to note that the connections present at our "new" collaboration stations were VGA, and not HDMI. Since the Apple TV device only supports HDMI output, we needed to purchase a couple of HDMI-to-VGA adapters. This allowed the students at these stations to broadcast their tablet to the LCD screens, using the Apple TV's Bluetooth connectivity as the conduit.

A final management challenge was the integration of the Bluetooth keyboards. Given that all of the Bluetooth keyboards were the same model, connecting them to the specific iPads proved to be problematic at first because each device had the same name. This is complicated by the fact that iOS 9 does not allow Bluetooth devices to be renamed; therefore, when the class would try and connect the keyboards, five copies of the same name would appear on everyone's device list - making it hard to distinguish which keyboard to connect to which iPad. Over time, students got used to this fact and actively checked to ensure that the keyboard they connected to the iPad was "their" keyboard.

\section{FUTURE Plans}

For the next academic year, five steps will be undertaken to correct deficiencies found during this initial pilot. First, all apps are being reviewed and, where appropriate, new apps are being sought and tested. Second, the author plans to implement a "training" program for all students in these courses. This set of content and activities should allow students, in the space of 1-2 class periods, to learn basic navigation techniques for the given technologies (iPads, keyboard, Apple TV). Third, the author plans to build an additional set of activities for students in the all of the previously participating courses, though with consideration of the aforementioned issues that appeared in 2015-2016. These activities will be designed to promote collaboration between multiple students and the use of the collaboration stations, while encouraging mobility. They will also be constructed with a manageable scope in terms of content (to help manage the screen size issue) and information product construction. In all cases, the activities will involve group presentations of work in some form. Fourth, the author is currently investigating the possibility of acquiring more precise styluses. Finally, the survey instruments are being revised to more fully assess the impact of the iPads on the stated outcomes.

\section{CONCLUSION}

The preceding study was designed as a pilot in the use of iPads in university computing courses. Building off the work of [11] and others, the year-long pilot provided valuable insight and guidance for future iPad integration. Students responded positively to the use of iPads, as was expected, and student perceptions of the iPads impact on problem-solving and collaborative skills were promising.
However, the assignments, activities, supporting technologies, and assessment mechanisms require some refinement in order to truly enhance the learning process and achieve the desired outcomes. Future plans for this study intend to address the aforementioned challenges discovered though this pilot and, in the future, utilize the iPads as an integral tool for building students' problemsolving and collaborative skills.

\section{ACKNOWLEDGMENTS}

The work described in this paper was funded by a grant provided by the Penn State Teaching and Learning with Technology (TLT) services group. The author wishes to thank the TLT staff for their generous support and assistance during this project. The author also wishes to thank Julie Meyer, Instructional Designer at Penn State, for her assistance and advice on this project.

\section{REFERENCES}

[1] Butcher, J. (2014). Can tablet computers enhance learning in further education? Journal of Further and Higher Education, 1-20.

[2] Couse, L. J., \& Chen, D. W. (2010). A tablet computer for young children? Exploring its viability for early childhood education. Journal of Research on Technology in Education, 43(1), 75-96.

[3] Czapracki A. \& Burrows, C. (2011). Bringing students and faculty together through mobile devices. In Proceedings of the 39th annual ACM SIGUCCS conference on User services (SIGUCCS '11). ACM, New York, NY, USA, 215-218.

[4] England, R. (2012). A software development course featuring iPAD APP construction. Journal of Computing Sciences in Colleges, 27(5), 93-100.

[5] Ferguson, J. M. (2016). Middle school students' reactions to a 1: 1 iPad initiative and a paperless curriculum. Education and Information Technologies, 1-14.

[6] Fischman, J. \& Keller, J. (2011). College Tech Goes Mobile. Chronicle of Higher Education, 58(1), 50.

[7] Goral, T. (2011). Take II tablets. University Business, 14(1), 46-49.

[8] Hesser, T. L., \& Schwartz, P. M. (2013). iPads in the science laboratory: Experience in designing and implementing a paperless chemistry laboratory course. Journal of STEM Education: Innovations and Research, 14(2), 5.

[9] Ihantola, P., Helminen, J. \& Karavirta, V. (2013). How to study programming on mobile touch devices: interactive Python code exercises. In Proceedings of the 13th Koli Calling International Conference on Computing Education Research (Koli Calling '13). ACM, New York, NY, USA, 51-58.

[10] Kheiravar, S., Lasserre, P. \& Campbell, R. (2012). A mobile application for collaborative learning. In Proceedings of the 14th international conference on Human-computer interaction with mobile devices and services companion (MobileHCI '12). ACM, New York, NY, USA, 137-142.

[11] Mang, C. \& Wardley, L. (2012). Effective Adoption of Tablets in Post-Secondary Education: Recommendations Based on a Trial of iPads in University Classes. Journal of Information Technology Education, 11(1), 301-317. 
[12] Nguyen, L., Barton, S. M., \& Nguyen, L. T. (2015). iPads in higher education-hype and hope. British Journal of Educational Technology, 46(1), 190-203.

[13] Palmer, J.D. (2011). Touchcasting digital lecture notes. Journal of Computing Sciences in Colleges. 26(4), 157-163

[14] Silverberg, L. (2013). Use of Doceri Software for iPad in Polycom and Resident Instruction Chemistry Classes. Journal of Chemical Education, 90(8), 1087-1089.

[15] Silverberg, L., Tierney, J. \& Bodek, M. (2014). Use of Doceri Software for iPad in Online Delivery of Chemistry Content. Journal of Chemical Education, 91(11), 19992001.

[16] Wainwright, K. (2012). Putting iPads in the hands of faculty. In Proceedings of the 40th annual ACM SIGUCCS conference on User services (SIGUCCS '12). ACM, New York, NY, USA, 139-144.

[17] Ward, N. D., Finley, R. J., Keil, R. G., \& Clay, T. G. (2013). Benefits and limitations of iPads in the high school science classroom and a trophic cascade lesson plan. Journal of Geoscience Education, 61(4), 378-384.
Public Administration from Penn State University in 2010, where his dissertation focused on the implementation of $1: 1$ programs in K-12.

Presently, he is a Senior Instructor of Information Sciences and Technology at Penn State University, Schuylkill campus. He has previously taught at Dickinson College and Harrisburg Area Community College. His research interests include Computer Science Education, K-12 integration of computer technology, and the intersection of public policy and IT. His research has previously appeared in Communications of the ACM, the Journal of Computing Sciences in Colleges, and other venues. His teaching interests include introductory Computer Science, computer programming, databases, and information and organizations.

Dr. Stone is an active member of the Association for Computing Machinery (ACM) and its Special Interest Group on Computer Science Education (SIGCSE).

\section{Authors' Profiles}

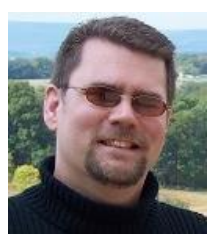

Dr. Jeffrey A. Stone received his Bachelor's Degree in Computer Science with an emphasis on Systems Programming from Shippensburg University in 1996. He received his Master's Degree in Computer Science from Shippensburg University in 1998. His Master's research focused on network design through simulation. He received his Ph.D. in

How to cite this paper: Jeffrey A. Stone,"Integrating Apple iPads into University Computing Courses", International Journal of Modern Education and Computer Science(IJMECS), Vol.8, No.9, pp.1-11, 2016.DOI: 10.5815/ijmecs.2016.09.01 